\title{
Understanding the mediating role of self-esteem between the relationship of self- forgiveness and human flourishing
}

\author{
Gyanesh Kumar Tiwari ${ }^{1}$, Ruchi Pandey ${ }^{1}$, Priyanka Parihar ${ }^{1}$, and Pramod Kumar Rai ${ }^{1}$ \\ ${ }^{1}$ Department of Psychology, School of Humanities \& Social Sciences, Doctor Harisingh \\ Gour Vishwavidyalaya, Sagar, 470003, Madhya Pradesh, India
}

May 18, 2020

\begin{abstract}
Background: Intrapersonal resources are significant preditors of human flourishing. The study examined the mediating role of self-esteem between the relationship of self-forgiveness and human flourishing.

Methods: A correlation research design was used. Two hundred and fourteen participants $\left(\mathrm{M}_{\mathrm{Age}}=22.07(1.80)\right)$ comprising 100 males $\left(\mathrm{M}_{\mathrm{Age}}=22.15(1.61)\right)$ and 114 females $\left(\mathrm{M}_{\mathrm{Age}}=22.00(1.95)\right)$ were chosen as the participants by a convenience sampling. Self-esteem, self-forgiveness and human flourishing were measured with standardized tools.

Results: The results showed significant interdependence among self-esteem, self-forgiveness and human flourishing as evident in their positive correlations. Self-esteem and self-forgiveness accounted for significant variability in human flourishing. These results are prerequisite condition to further carry out mediation analysis that showed self-esteem to emerge as a significant partial mediator between the relationships between self-forgiveness and human flourishing.

Conclusions: Self-esteem represents self-worth and personal values that are essential ingredients to prepare a person to forgive himself/herself that, in turn, may cultivate positive affect and cognition leading one to achieve flourishing. Self-esteem helps to understand transgressing situations and the exact role of the various stakeholders. These positive attributions may have facilitated self-forgiveness and finally flourishing. It was evident that both self-esteem and self-forgiveness are relevant to understand human flourishing and the impacts of self-forgiveness are mediated by self-esteem. In essence, intrapersonal resources carry significance to enhance human flourishing. The findings represent a significant contribution to understanding the relationships among self-esteem, self-forgiveness and human flourishing.
\end{abstract}

\section{Keywords}

self-esteem, self-forgiveness, human flourishing, mediation analysis.

\section{Introduction}

Forgiveness has been encouraged for thousands of years by major world religions. Social scientists have only recently begun to develop theoretical models and conducted studies on forgiveness (Toussaint et al., 2020). Given that the scientific study of forgiveness is relatively new, it seems sensible for scientists to learn about long-lasting scientific conceptualizations of forgiveness. Examination of scientific perspectives on forgiveness can benefit researchers to shed light on the psychological process involved in forgiveness (Griffin et al., 2020). Forgiveness is a positive human virtue that reflects lack of resentment and involves benevolence, compassion and love towards a transgressor (Thompson et al., 2005; Worthington, 2001). Forgiveness helps achieve the development and restoration of self and interpersonal relationships (McCullough, 2008), mental health (Webb \& Toussaint, 2020; Worthington \& Scherer, 2004) and physical health (Lawler et al., 2003; Toussaint 
et al., 2020). Forgiveness interventions have been reported to be effective to benefit individuals facing interpersonal and emotional problems and promote well-being (Baskin \& Enright, 2004). The positive impacts of forgiveness extend from intrapersonal, interpersonal and collective to organization all levels (Aquino et al., 2006; Noor et al., 2008; Stone, 2002). Self-forgiveness, interpersonal forgiveness, collective forgiveness and organizational forgiveness are the various forms of forgiveness that are regulated by dissimilar mechanisms and processes and carry different implications of positive life outcomes of people (Stone, 2002; Toussaint \& Webb, 2005).

Self-forgiveness is one form of forgiveness which refers to a willingness to abandon self-resentment in the face of one's own acknowledged objective wrong while fostering compassion, generosity, and love toward oneself (Enright, 1996). Moreover, it involves a set of motivational changes whereby one becomes decreasingly motivated to avoid stimuli associated with the offense, decreasingly motivated to retaliate against the self, and increasingly motivated to act benevolently toward the self (Hall \& Fincham, 2005). Hall and Fincham (2005) have proposed the first model of self-forgiveness that speculated the development of state self-forgiveness in which one's attributions and the severity of the transgression reported to contributing to the development of state shame and guilt. Besides, guilt, conciliatory behaviours toward the victim or towards a higher power, combined with perceived forgiveness from these sources, may impede or enhance self-forgiveness. It has been reported that attributions, empathy, and shame were unrelated to self-forgiveness, and only transgression severity, guilt, conciliatory behaviours, and perceived forgiveness influenced the development of self-forgiveness beyond the effect of time (Hall \& Fincham, 2008).

The self-forgiveness model of Hall and Fincham (2008) was criticized by Rangganadhan and Todorov (2010) who argued that guilt positively affects self-forgiveness via prompting both other-oriented empathy and conciliatory behaviour, while shame negatively affects self-forgiveness, both individually and by increasing personal distress empathy, or the experience of self-oriented distress at the recognition of another's discomfort. McConnell et al. (2012) tested the original model of Hall and Fincham (2005) again and suggested an alternative model that described the role of severity of the offense, guilt, conciliatory behaviour and perceived forgiveness accounting the greatest variance in self-forgiveness. Thus, it is noticeable that the nature and dynamics of self-forgiveness are very complicated as a multitude of antecedents and correlates have been identified to regulate self-forgiveness. Many intrapersonal and interpersonal factors such as perceived severity of transgression (Fincham et al., 2005); absence of apology (McCullough et al., 1998), the nature of the relationship (McNulty, 2011), emotions (McCullough et al., 1998), cognitions (McCullough et al., 2007) and personality attributes (Berry et al., 2005) are closely linked with self-forgiveness.

The above discussion shows that self-forgiveness is new to the psychological inquiry and its initial conceptualization lends its genesis from interpersonal forgiveness. This gap was bridged with the efforts of Mudgal and Tiwari (2017) who proposed a model of self-forgiveness deriving form an extensive and empirical study of employing a mixed methods research design. According to this model, there are three components of selfforgiveness that includes realization \& reparation, guilt and attrition. The psychometric properties of the scale derived from this study are appreciating. It is explicit that there has been a dearth of scientific studies on self-forgiveness as compared to interpersonal forgiveness. The initial theorizing and empirical testing have reported self-forgiveness interventions effective and encouraging. It is relevant to discuss that self-forgiveness has recently attracted the attention of the researchers due to its proved effectiveness in clinical interventions and development of psychometric measures (Scheier et al., 1994; Scherer et al., 2011).

Many correlates of self-forgiveness have been identified. Self-esteem is one important construct that has shown its significant implications to understand self-forgiveness. The researchers have suggested that the individuals who experience an attack on their self-esteem are less able to forgive. It is the self-esteem that ascertains the level of threat due to any transgressions and thus, it may be relevant to for self-forgiveness (Strelan \& Zdaniuk, 2015). Recognizing the significant role of self-esteem in many indices of performance and psychological processes, the researchers have suggested the need to test the process driving the relationship between self-esteem and self-forgiveness (Strelan \& Zdaniuk, 2015). The lower level of self-esteem encourages people to enter self-protection and develop avoidance that may affect self-forgiveness negatively. It has 
been reported that excess self-protection due to low self-esteem may also result in decreased availability of psychological resources to devote to forgiveness (Strelan \& Zdaniuk, 2015). Transgression severity has consistently been shown to be a barrier to forgiveness (Fincham et al., 2005). There is a strong need to examine the positive and protecting self-processes to account for their impacts on forgiveness (Strelan \& Zdaniuk, 2015).

A perusal of previous studies showed that very little is known about the extent to which an individual's self-esteem affects forgiveness (Strelan \& Zdaniuk, 2015). Some studies have been conducted employing trait self-esteem with mixed findings. A meta-analytic review showed that there was a very weak relationship between trait self-esteem and situation-specific forgiveness (Fehr et al., 2010) whereas some studies have reported self-esteem to play a significant role in self-forgiveness (Strelan \& Zdaniuk, 2015). It may be argued that self-forgiveness and self-esteem may have a bi-directional relationship and may affect each other depending on the situations. For example, the transgression situation in which the individuals commit wrongdoing may also affect the self-esteem of individuals and may consequently impact their forgiveness. With this backdrop of the arguments and facts, the present study attempted to understand the mediating role of self-esteem in shaping the relationship between self-forgiveness and human flourishing (well-being).

\section{Objectives}

The following were the objectives of the study:

(1) To understand the nature of association among self-forgiveness, self-esteem and human flourishing.

(2) To estimate the variance accounted for by gender, age, self-forgiveness and self-esteem in accounting variability in the scores of human flourishing measure.

(3) To understand the meditational role of self-esteem for the relationships self-esteem and human flourishing.

\section{Hypotheses}

Based on the understanding of the previous studies, the following hypotheses have been formulated:

(4) There will be positive correlations among self-esteem, self-forgiveness and human flourishing.

(5) Gender, age, self-esteem and self-forgiveness will account for significant variance in the scores of human flourishing.

(6) Self-esteem will positively mediate the relationship between self-forgiveness and human flourishing.

\section{Methods and Procedure}

\section{Participants}

A convenient sampling method was used to recruit the participants in the study. Data were collected from 300 students attending different Schools of Studies, such as Arts, Commerce, Science and Law [BLINDED FOR REVIEW]. Initially, 300 participants with an equal number of males and females were recruited for the study. After screening the outliers as per the suggestion of Donald (2016), the data of only 100 males age ranging 21 years to 24 years $\left(\right.$ Mean $\left._{\text {Age }}=22.15, \mathrm{SD}_{\mathrm{Age}}=1.61\right)$ and 114 females age spanning from 22 years to 24 years $\left(\mathrm{Mean}_{\mathrm{Age}}=22.00, \mathrm{SD}_{\mathrm{Age}}=1.95\right)$ were used for the final statistical analysis. The males and female did not differ in their mean age $(\mathrm{t}=.608, \mathrm{df}=212, p=.544)$.

All the relevant demographic details relevant to the study were taken from the participants such as age, sex, domicile, religion and education. Before distributing the set of questionnaires, the researchers explained the 
instructions and debriefed about the basic objectives of the study. Majority of the participants belonged to middle socioeconomic status. All the participants were fluent in Hindi and English languages although their local dialect was Bundelkhandi. The religious affiliations of the participants were diverse. Majority of them were Hindu (63.12\%) while the rest were Muslim (17.89\%), Jain (15.61\%) and Christian (3.38\%). The data were collected in the classroom setting voluntarily with the due permission from the competent authority.

\section{Psychometric Tools}

All the scales employed in the present were first translated by three researchers from English to Hindi followed by retranslation from Hindi to English according to the suggestions suggestion of the earlier researchers (Behr, 2017; Brislin, 1970). Besides, their face validity was established according to the basic constructs before the final decision to use these tools was taken. The researchers had gone through the various constructs and validated each item of the scales. The following psychometric tools were employed to collect data:

\section{Self-esteem Scale}

Self-Esteem Scale is a uni-dimensional scale having 10-items that measures global self-worth by measuring both positive and negative feelings about the self (Rosenberg, 1965). The items seek an answer on a 4-point Likert scale format ranging from strongly agree to strongly disagree. It has been reported that people high in self-esteem show high attractiveness, better relationships and make better impressions on other people. High self-esteem has also been shown to have a strong relation to happiness and well-being (Baumeister et al., 2003; Pandey et al., 2019) and lowered depression (Baumeister et al., 2003).

\section{Self-forgiveness Scale}

The self-forgiveness scale was developed by Mudgal and Tiwari (2017) standardized on Indian population adopting exploratory mixed methods design. It consisted of 30 items with seven-point scale (1-very strongly disagree, 2-strongly disagree, 3-somewhat disagree, 4- neutral,5-somewhat agree, 6- strongly agree, 7-very strongly agree). The scale purports to measure three dimensions of self -forgiveness: realization and reparation, guilt and attribution with the help of 19 items, 6 items and 5 items, respectively. The reliability was estimated by computing Cronbach's alpha which were $.90, .70, .62$ and .77 for the first, second, third components of self-forgiveness and overall scale, respectively. Its validity was estimated by computing correlation among the scores of this scale and overall quality of life component of (World Health Organization, 1996) that was 0.261. The coefficients of Cronbach Alpha for the scores on realization and reparation, guilt, attribution and overall self-forgiveness scale were estimated to be $0.927,0.642,0.600$ and 0.858 , respectively (Pandey et al., 2020).

\section{Mental Health Continuum-Short Form (MHC-SF)}

Human flourishing was measured with the help of Mental Health Continuum-Short Form (Keyes, 2005). The scale is based on the model of flourishing having theoretical origin from three sources: studies on emotional well-being (Diener et al., 1999), studies on hedonic (subjective or emotional) well-being and eudaimonic (psychological) well-being (Ryff, 1989) and studies on social well-being (Keyes, 1998). The scale consists of 14-item. Each item is scored according to respondents' experiences over the last month on a 6-point Likert scale ('never', 'once or twice', 'about once a week', '2 or 3 times a week', 'almost every day', or 'every day'). Three items represent emotional well-being, six items represent psychological well-being and five items represent social well-being. It has been reported that internal consistency reliability for each of the three sets of measures-emotional, psychological, and social well-being-in the MHC short and long forms have all been $>.80$ (Keyes, 2005). The Cronbach Alpha for the scores of the participants of the present study on hedonic, psychological, social and eudaimonic dimensions of well-being were estimated to be $0.817,0.709$, 0.710 and 0.801 , respectively. For the scores of the participants on the overall human flourishing measure, the Cronbach Alpha was computed to be 0.848 . 


\section{Procedure}

The research proposal was put before the Ethics committee [BLINDED FOR REVIEW]. After its approval, the scales to be employed in the study were prepared and the participants were consulted after due permission. After getting written permission to participate in the study from each participant, the data collection was started using small groups of 20 to 25 participants to enhance the reliability and consistency of the replies of the participants. The researchers (second and third) read the written instructions first in an audible manner before they were asked to put their responses for the items of the scales. In this manner, various questionnaires were administered and the responses of the participants were collected.

\section{Data Analysis}

As the task of data collection was over, the scoring was done and the data were arranged according to the need of the statistical methods used. The mean, standard deviations, coefficients of correlation, hierarchical regression analysis and mediation analysis were computed adopting the criteria of 5000 bootstrap samples with the help of SPSS 25v available in the Department of Psychology of University.

\section{Results}

\section{Preliminary Analyses}

The mean, standard deviation and coefficient of correlation and hierarchical regression were employed as the preliminary analyses. The results exhibited that the male and female participants did not differ in their mean scores on self-forgiveness and self-esteem. Conversely, the male participants $(\mathrm{M}=12.49, \mathrm{SD}=2.10)$ achieved significantly $(\mathrm{t}(212)=2.84, p=.005)$ higher mean score on hedonic well-being as compared to their female counterparts $(\mathrm{M}=11.46, \mathrm{SD}=3.07)$ (Table 1).

Table 1. Coefficients of correlations among Gender, Age, Self-Forgiveness, Self-esteem and Human Flourishing of the participants $(\mathrm{N}=214)$

Measures

Mean (SD)

Gender

Age

SF

SE

HF

Gender

$1.53(0.50)$

1

Age 
SE

HF

77.15 (16.38)

$-.266^{* *}$

$.207^{* *}$

$.315^{* *}$

$.218^{* *}$

Note 1: $\mathbf{H F}=$ Human Flourishing, $\mathbf{S E}=$ Self-esteem, $\mathbf{S F}=$ Self-forgiveness.

Note 2:*. Correlation is significant at the 0.05 level, ${ }^{* *}$. Correlation is significant at the 0.01 level

Positive correlations were observed among the scores of self-esteem and human flourishing $(\mathrm{r}=.218, \mathrm{p}$ $=.000)$, between self-esteem and self-forgiveness $(\mathrm{r}=.234, \mathrm{p}=.000)$ and between human flourishing and self-forgiveness $(\mathrm{r}=.315, \mathrm{p}=.000)$ (See Table 1$)$.

The hierarchical regression was employed to partial out the relative contributions of gender, age, selfforgiveness and self-esteem in accounting for variability in the scores of human flourishing measure of the participants. The hierarchical regression analysis showed that the predicted value of human flourishing for 
males was 8.453 units higher than for females and 1.790 units for change in per year age change. Similarly, the value of $\mathrm{R} 2$ showed that $10.90 \%$ variations in the scores of human flourishing accounted for by combined effects of gender and age in model $1(\mathrm{R} 2=.109, \mathrm{~F}(1,211)=12.96, \mathrm{p}=.000)$. In model 2 , it was explicit that the predicted value of human flourishing increased by .292 units for each unit of self-forgiveness. Further, self-esteem accounted for $19.40 \%$ variation in the scores of human flourishing of the participants $(\mathrm{R} 2=.194$, $\mathrm{F}(1,210)=22.06, \mathrm{p}=.000)$. In Model 3 , the predicted value of human flourishing increased by .185 units for each unit of self-esteem that accounted for $22.60 \%$ variation in the scores of the human flourishing of the participants $(\mathrm{R} 2=.226, \mathrm{~F}(1,209)=8.54, \mathrm{p}=.004)$ (see Table 2$)$. It is evident that age and gender cumulatively accounted for 10.90 per cent variability in human flourishing and the addition of self-forgiveness caused another 8.50 per cent change in the criterion measure. Lastly, the entering of self-esteem at level three accounted for another 3.20 per cent variability in human flourishing (see Table 2). As self-forgiveness, self-esteem and human flourishing yielded significant positive correlations, a need for understanding the mediating role between the rest two was necessitated that has been presented in the ensuing section.

Table 2. Summary of Hierarchical Regression Analysis for Variables Predicting Human Flourishing of the participants $(\mathrm{N}=214)$

\begin{tabular}{llll}
\hline Predictors & Model 1 & Model 2 & Model 3 \\
& $\mathrm{~B}$ & $\mathrm{SE}$ & $\beta$ \\
Gender & -8.453 & 2.130 & -.258 \\
Age & 1.790 & .593 & .196 \\
$\mathrm{SF}$ & & & \\
$\mathrm{SE}$ & & .194 & .226 \\
$\mathrm{R}^{2}$ & .109 & .085 & .032 \\
{$[?] \mathrm{R}^{2}$} & .109 & $22.06^{* *}$ & $8.54^{* *}$ \\
{$[?] \mathrm{F}$} & $12.96^{* *}$ & & \\
\hline
\end{tabular}

Note 1: All standardized regression coefficients $(\beta)$ belong to final step of the analyses. df Model $1=(2$, 211) and Model $2=(3,208)$, Model $3(1,207)$

Note 2: $\mathbf{H F}=$ Human Flourishing, $\mathbf{S E}=$ Self-esteem, $\mathbf{S F}=$ Self-forgiveness.

Note 3:*. Correlation is significant at the 0.05 level, ${ }^{* *}$. Correlation is significant at the 0.01 level.

\section{Mediation Analysis}

It has been suggested that mediation analysis is to be preferred when the basic aim of a study is to identify and explore the mechanisms involved behind the relationship between predictors and outcome variables (Baron \& Kenny, 1986). A mediator analysis was performed to test the third hypothesis, by using Andrew Hayes' PROCESS plug-in for SPSS version 25 (Field, 2013). To investigate the hypothesis that the relationship between self-forgiveness and human flourishing was mediated by self-esteem, a simple mediation model was applied. We employed PROCESS Model 4 (simple mediation) to estimate regression coefficients and followup bootstrap analyses with 5,000 bootstrap samples to estimate $95 \%$ bias-corrected confidence intervals for specific and total indirect effects. In our study human flourishing is the dependent variable $(\mathrm{Y})$ that is regressed on self-forgiveness $(\mathrm{X})$, self-esteem $(\mathrm{M})$ and $\mathrm{M}$, is itself regressed on $\mathrm{X}$. Thus, $\mathrm{M}$ represents the mediator variable. The indirect effect estimate of self-esteem was 0.022 , with the $95 \%$ confidence interval not encompassing 0 (0.011-0.004), indicating a statistically significant mediation effect. Since all equations of the total effect, direct effect and indirect effect are showing significant results hence it indicates self-esteem partially mediates between the relationship of self-forgiveness and human flourishing.

Table 3. Showing total, direct and indirect effects of Self-Forgiveness on Human Flourishing mediated by Self-esteem 


\begin{tabular}{|c|c|c|c|c|}
\hline & Effect & SE & $\mathrm{CI}_{\text {low }}$ & $\mathrm{CI}_{\text {up }}$ \\
\hline Total effect of self-forgiveness on human flourishing & 0.199 & 0.041 & 0.118 & 0.281 \\
\hline Direct effect of self-forgiveness on human flourishing & 0.177 & 0.042 & 0.094 & 0.263 \\
\hline Indirect effect of self-forgiveness on human flourishing mediated by positive self-esteem & 0.022 & 0.011 & 0.004 & 0.048 \\
\hline
\end{tabular}

\section{Discussion}

The findings of the study have evinced the abiding role of some demographic factors (gender and age), selfforgiveness and self-esteem in shaping the nature and extent of the human flourishing of the participants. Except for gender that was negatively correlated with human flourishing, age, self-forgiveness and self-esteem were positively correlated with human flourishing. The hierarchical regression analyses evinced that that gender, age, self-forgiveness and self-esteem contributed significantly to the scores of human flourishing. The findings showed that gender (.266) and self-forgiveness (.247) emerged as the most significant predictors of human flourishing followed by self-esteem (.185) and age (.178) as depicted by beta $(\beta)$ values in Model 3 (see Table 3). More importantly, mediation analysis evinced that self-esteem played a significant mediating role (partial mediation) the relationship between self-forgiveness and human flourishing.

The negative correlations among gender and other measures showed that females showed lower attainments on these measures as compared to their male counterparts. Gender differences in the acquisition of selfforgiveness, self-esteem and human flourishing of the participants may be due to the fact that the Indian society still carries large and perceptible gender disparities in the availability of various resources and opportunities (Ram et al., 2014). Similar findings regarding gender differences on these measures have also reported that suggested dissimilar availabilities of the socio-cultural and socialization patterns along with positive resources to cause such differences (Pandey et al., 2019, 2020).

A positive correlation between self-forgiveness and human flourishing was observed. It may be posited that realizing one's role in transgressions and involving oneself in repairing the damage caused by such transgressions may result in decreasing negative emotions and increasing positive emotions. Higher selfforgiveness may also culminate in improved interpersonal and social relationships, positive attributions and satisfaction that may be directly assumed to shape human flourishing. The significant mediation of selfesteem between the relationship of self-forgiveness and human flourishing was observed. It might have caused by the fact that positive self-evaluations and personal values, the major ingredients of self-esteem, facilitated the achievement of flourishing by the individuals who were more self-forgiving.

In other words, self-esteem carries self-satisfaction, self-attitude, self-worth, self-efficacy, self-respect, social comparison, self-pride, self-perception, relative strengths and feeling of being virtuous. Self-esteem has been reported to have close links with happiness, positive emotions, self-evaluation, positive mood regulation, optimistic thinking and optimal functioning that buffer the effects of stress caused by pain, failure and adversities of life. It has also been observed that self-esteem benefits individuals in two ways: enhanced initiative and pleasant feelings (Baumeister et al., 2003). Similarly, some other researchers have argued that higher self-esteem may increase the accessibility of psychological resources like self-compassion necessary for individuals to invest in forging self (Pandey et al., 2019; Strelan \& Zdaniuk, 2015). Positive and higher selfesteem may also facilitate self-forgiveness and finally flourishing by helping the person to assess his/her role in causing pain to others and necessary steps to be undertaken to repair the damage caused by it (Fincham et al., 2005). Small sample, a limited number of psychological constructs, selection of only adult student sample and use of the only quantitative method for the data collection were the major limitations of the study. 


\section{Summary and Conclusions}

The results showed a close and significant interdependence among self-esteem, self-forgiveness and human flourishing as evident in their positive correlations. Moreover, self-esteem and self-forgiveness accounted for significant variability in human flourishing (regression analysis). These results are pre-requisite condition to further carry out mediation analysis that showed self-esteem to emerge as a significant partial mediator between the relationships between self-forgiveness and human flourishing measures. Self-esteem represents self-worth and personal values that are essential ingredients to prepare a person to forgive himself/herself that, in turn, may cultivate positive affects and cognitions leading one to achieve flourishing. Moreover, selfesteem helps to understand transgressing situations and the exact role of the various stakeholders. These positive attributions may have facilitated self-forgiveness and finally flourishing of the participants.

\section{Implications and Directions for Future Researchers}

There is ample opportunity for future researchers to further extend their contributions to the field of selfforgiveness, self-esteem and human flourishing. Understanding the developmental trends in self-forgiveness and self-esteem in the context of human flourishing may be a new and worthy addition to this field. More qualitative studies may be carried out to explore further dimensions of self-forgiveness, self-esteem and human flourishing in the existing theories of their similarities and dissimilarities in light of individualistic and collectivistic cultural values. The cross-cultural investigations of these constructs may strengthen the understanding of the relationship of these positive constructs. The study of self-forgiveness and self-esteem can be made even more useful by incorporating other positive psychological constructs.

\section{Statement of Funding}

The authors have no funding to report.

\section{Declaration of Conflicting Interest}

The author(s) declared no potential conflicts of interest with respect to the research, authorship, and/or publication of this article.

\section{References}

Aquino, K., Tripp, T. M., \& Bies, R. J. (2006). Getting even or moving on? Power, procedural justice, and types of offense as predictors of revenge, forgiveness, reconciliation, and avoidance in organizations. Journal of Applied Psychology, 91 (3), 653-668. https://doi.org/10.1037/0021-9010.91.3.653

Baron, R. M., \& Kenny, D. A. (1986). The moderator-mediator variable distinction in social psychological research: Conceptual, strategic, and statistical considerations. Journal of Personality and Social Psychology, 51(6), 1173-1182. https://doi.org/10.1037/0022-3514.51.6.1173

Baskin, T. W., \& Enright, R. D. (2004). Intervention Studies on Forgiveness: A Meta-Analysis. Journal of Counseling \& Development, 82(1), 79-90. https://doi.org/10.1002/j.1556-6678.2004.tb00288.x

Baumeister, R. F., Campbell, J. D., Krueger, J. I., \& Vohs, K. D. (2003). Does High Self-Esteem Cause Better Performance, Interpersonal Success, Happiness, or Healthier Lifestyles? Psychological Science in the Public Interest, 4(1), 1-44. https://doi.org/10.1111/1529-1006.01431 
Behr, D. (2017). Assessing the use of back translation: The shortcomings of back translation as a quality testing method. International Journal of Social Research Methodology, 20(6), 573-584. https://doi.org/10.1080/13645579.2016.1252188

Berry, J. W., Worthington, E. L., Wade, N. G., van Oyen Witvliet, C., \& Kiefer, R. P. (2005). FORGIVENESS, MORAL IDENTITY, AND PERCEIVED JUSTICE IN CRIME VICTIMS AND THEIR SUPPORTERS. Humboldt Journal of Social Relations, 29(2), 136-162. JSTOR.

Brislin, R. W. (1970). Back-Translation for Cross-Cultural Research. Journal of Cross-Cultural Psychology, 1(3), 185-216. https://doi.org/10.1177/135910457000100301

Diener, E., Suh, E. M., Lucas, R. E., \& Smith, H. L. (1999). Subjective well-being: Three decades of progress. Psychological Bulletin, 125(2), 276-302. https://doi.org/10.1037/0033-2909.125.2.276

Donald, S. (2016). Data Screening using SPSS for beginner: Outliers, Missing Values and Normality [Workshop]. Institute of Borneo Studies Workshop Series 2016 (2)3, Institute of Borneo Studies, UNIMAS. https://ir.unimas.my/id/eprint/12266/

Enright, R. D. (1996). Counseling Within the Forgiveness Triad: On Forgiving, Receiving Forgiveness, and Self-Forgiveness. Counseling and Values, 40(2), 107-126. https://doi.org/10.1002/j.2161007X.1996.tb00844.x

Fehr, R., Gelfand, M. J., \& Nag, M. (2010). The road to forgiveness: A meta-analytic synthesis of its situational and dispositional correlates. Psychological Bulletin, 136(5), 894-914. https://doi.org/10.1037/a0019993

Field, A. (2013). Discovering Statistics using IBM SPSS Statistics. SAGE Publications Ltd.

Fincham, F. D., Jackson, H., \& Beach, S. R. H. (2005). Transgression Severity and Forgiveness: Different Moderators for Objective and Subjective Severity. Journal of Social and Clinical Psychology, 24(6), 860-875. https://doi.org/10.1521/jscp.2005.24.6.860

Griffin, B. J., Cowden, R. G., \& Shawkey, L. A. (2020). Bibliography of narrative reviews and meta-analyses on forgiveness (2004-2018). In E. L., Worthington, Jr., \& N. G., Wade, (Eds.), Handbook of forgiveness (Second Edition, pp. 335-344). Routledge.

Hall, J. H., \& Fincham, F. D. (2005). Self-Forgiveness: The Stepchild of Forgiveness Research. Journal of Social and Clinical Psychology, 24(5), 621-637. https://doi.org/10.1521/jscp.2005.24.5.621

Hall, J. H., \& Fincham, F. D. (2008). The Temporal Course of Self-Forgiveness. Journal of Social and Clinical Psychology, 27(2), 174-202. https://doi.org/10.1521/jscp.2008.27.2.174

Keyes, Corey L. M. (2005). Mental Illness and/or Mental Health? Investigating Axioms of the Complete State Model of Health. Journal of Consulting and Clinical Psychology, 73(3), 539-548. https://doi.org/10.1037/0022-006X.73.3.539

Keyes, Corey Lee M. (1998). Social Well-Being. Social Psychology Quarterly, 61(2), 121. https://doi.org/10.2307/2787065

Lawler, K. A., Younger, J. W., Piferi, R. L., Billington, E., Jobe, R., Edmondson, K., \& Jones, W. H. (2003).

A change of heart: Cardiovascular correlates of forgiveness in response to interpersonal conflict. Journal of Behavioral Medicine, 26(5), 373-393.

McConnell, J. M., Dixon, D. N., \& Finch, W. H. (2012). An Alternative Model of Self-Forgiveness. The New School Psychology Bulletin, 9(2), 35-51.

McCullough, M. E. (2008). Beyond revenge: The evolution of the forgiveness instinct (1st ed). Jossey-Bass. 
McCullough, M. E., Bono, G., \& Root, L. M. (2007). Rumination, emotion, and forgiveness: Three longitudinal studies. Journal of Personality and Social Psychology, 92(3), 490-505. https://doi.org/10.1037/00223514.92.3.490

McCullough, M. E., Rachal, K. C., Sandage, S. J., Worthington, E. L., Brown, S. W., \& Hight, T. L. (1998). Interpersonal forgiving in close relationships: II. Theoretical elaboration and measurement. Journal of Personality and Social Psychology, 75 (6), 1586-1603. https://doi.org/10.1037/0022-3514.75.6.1586

McNulty, J. K. (2011). The Dark Side of Forgiveness: The Tendency to Forgive Predicts Continued Psychological and Physical Aggression in Marriage. Personality and Social Psychology Bulletin, 37(6), 770-783. https://doi.org/10.1177/0146167211407077

Mudgal, S., \& Tiwari, G. K. (2017a). The Self-forgiveness Scale. Unpublished Scale, Department of Psychology, School of Humanities \& Social Sciences, Doctor Harisingh Gour Vishwavidyalaya, Sagar, Madhya Pradesh, India.

Noor, M., Brown, R., Gonzalez, R., Manzi, J., \& Lewis, C. A. (2008). On Positive Psychological Outcomes: What Helps Groups With a History of Conflict to Forgive and Reconcile With Each Other? Personality and Social Psychology Bulletin, 34(6), 819-832. https://doi.org/10.1177/0146167208315555

Pandey, R., Tiwari, G. K., Parihar, P., \& Rai, P. K. (2019). Positive, not negative, self-compassion mediates the relationship between self-esteem and well-being. Psychology and Psychotherapy: Theory, Research and Practice, papt.12259. https://doi.org/10.1111/papt.12259

Pandey, R., Tiwari, G. K., Parihar, P., \& Rai, P. K. (2020). The relationship between self-forgiveness and human flourishing: Inferring the underlying psychological mechanisms. Polish Psychological Bulletin, 51(1), 29-42. https://doi.org/10.24425/ppb.2020.132649

Ram, U., Strohschein, L., \& Gaur, K. (2014). Gender Socialization: Differences between Male and Female Youth in India and Associations with Mental Health. International Journal of Population Research, 2014, 1-11. https://doi.org/10.1155/2014/357145

Rangganadhan, A. R., \& Todorov, N. (2010). Personality and Self-Forgiveness: The Roles of Shame, Guilt, Empathy and Conciliatory Behavior. Journal of Social and Clinical Psychology, 29(1), 1-22. https://doi.org/10.1521/jscp.2010.29.1.1

Rosenberg, M. (1965). Society and the adolescent self-image. Princeton University Press.

Ryff, C. D. (1989). Happiness is everything, or is it? Explorations on the meaning of psychological wellbeing. Journal of Personality and Social Psychology, 57(6), 1069-1081. https://doi.org/10.1037/00223514.57.6.1069

Scheier, M. F., Carver, C. S., \& Bridges, M. W. (1994). Distinguishing optimism from neuroticism (and trait anxiety, self-mastery, and self-esteem): A reevaluation of the Life Orientation Test. Journal of Personality and Social Psychology, 67(6), 1063-1078. https://doi.org/10.1037/0022-3514.67.6.1063

Scherer, M., Worthington, E. L., Hook, J. N., \& Campana, K. L. (2011). Forgiveness and the Bottle: Promoting Self-Forgiveness in Individuals Who Abuse Alcohol. Journal of Addictive Diseases, 30(4), 382395. https://doi.org/10.1080/10550887.2011.609804

Stone, M. (2002). Forgiveness in the workplace. Industrial and Commercial Training, 34(7), 278-286. https://doi.org/10.1108/00197850210447282

Strelan, P., \& Zdaniuk, A. (2015). Threatened State Self-Esteem Reduces Forgiveness. Self and Identity, 14 (1), 16-32. https://doi.org/10.1080/15298868.2014.889034

Thompson, L. Y., Snyder, C. R., Hoffman, L., Michael, S. T., Rasmussen, H. N., Billings, L. S., Heinze, L., Neufeld, J. E., Shorey, H. S., \& Roberts, J. C. (2005). Dispositional Forgiveness of Self, Others, and Situations. JOURNAL OF PERSONALITY, 73(2), 313-360. 
Toussaint, L. L., \& Webb, J. R. (2005). Gender Differences in the Relationship Between Empathy and Forgiveness. The Journal of Social Psychology, 145(6), 673-685. https://doi.org/10.3200/SOCP.145.6.673686

Toussaint, L. L., Worthington Jr, E. L., Williams, D. R., \& Webb, J. R. (2020). Forgiveness and Physical Health. In E. L. Worthington Jr. \& N. G. Wade (Ed.), Handbook of Forgiveness (Second Edition, pp. 178-187). Routledge.

Webb, J. R., \& Toussaint, L. L. (2020). Forgiveness, Well-Being, and Mental Health. In E. L., Worthington, Jr., $\&$ N. G., Wade, (Eds.), Handbook of forgiveness (Second Edition, pp. 188-197). Routledge.

World Health Organization. (1996). WHOQOL-BREF: Introduction, administration, scoring and generic version of the assessment: field trial version, December 1996. https://apps.who.int/iris/handle/10665/63529

Worthington, E. L. Jr. (2001). Five steps to forgiveness: The art and science of forgiving. Crown.

Worthington, E. L., \& Scherer, M. (2004). Forgiveness is an emotion-focused coping strategy that can reduce health risks and promote health resilience: Theory, review, and hypotheses. Psychology \& Health, 19(3), 385-405. https://doi.org/10.1080/0887044042000196674 